\title{
TRADISI PENGANUGERAHAN IJAZAH DALAM SISTEM PENDIDIKAN ISLAM: KAJIAN SELAYANG PANDANG
}

\author{
Mesut Idriz 1) * \\ Idha Nurhamidah 2) $^{* *}$ \\ ${ }^{1}$ Department of History and Islamic Civilization \\ University of Sharjah, United Arab Emirates \\ 2 Program Studi Sastra Inggris \\ Universitas Islam Sultan Agung, Semarang \\ *E-mail: idhanurhamidah@unissula.ac.id
}

\begin{abstract}
The current article aimed at presenting an overview of types, requirements and procedures of certification in Islam education for the students who have passed the examination in order for countries outside United Arab Emirates. Core materials on the subject were compiled from various resources to guarantee the validity of the information. It turned out that there were a number of concepts of certification pertinent to etymology and practices. One distinctive issue of certification was that, in Islam education, certification was attached to the authority of professor or sheikh, not the institution, and the government has no right whatsoever with respect to certification. This, in fact, differentiates certification in Islam World from that practiced in the West.
\end{abstract}

Keywords: Certificate, Certification, Etymological Concept, Islam Education System

\begin{abstract}
Abstrak
Dalam Sistem Pendidikan Islam, terdapat tradisi pengijazahan bagi para mahasiswa yang dinyatakan lulus. Makalah ini menyajikan selayang pandang jenis-jenis, syarat-syarat serta prosedur pengijazahan agar informasi tentang sistem pengijazahan tersebut dapat disebar luaskan ke luar negara Uni Emirat Arab. Materi dalam makalah ini merupakan rangkuman sari yang diambil dari berbagai literatur resmi agar terjamin validitas informasinya. Dalam pembahasannya, ternyata terdapat beberapa konsep ijazah menurut etimologi dan prakteknya. Satu butir yang sangat menonjol dalam prosedur pengijazahan adalah bahwa ijazah dianugrahkan oleh professor, sheikh, ulama, bukan institusi; dan pemerintah tidak berwenang melakukan intervensi. Disamping itu dalam ijazah disebutkan mengenai mata pelajaran berikut kitab-kitab yang telah diselesaikan lengkap dengan silsilah penyampai/perawi yang bermuara pada penulis kitab-kitab tersebut. Hal-hal inilah yang membedakan sistem pengijazahan dalam Pendidikan Islam dengan Pendidikan Barat.
\end{abstract}

Kata kunci: Ijazah, Konsep Etimologis, Prosedur, Sistem Pendidikan Islam

\section{PENDAHULUAN}

Dalam sistem pendidikan tentunya ada bukti otentik bahwa peserta didik (santri, siswa, mahasiswa) telah menyelesaikan program studi tertentu. Bukti otentik tersebut harus dapat diterima secara universal sebagai bukti resmi dan berkekuatan hukum dan dapat digunakan oleh lulusan (graduate) untuk kepentingan yang berhubungan 
dengan kepemilikan bukti otentik tersebut yang berupa ijazah. Namun demikian, kiranya masih banyak di kalangan masyarakat yang belum memahami bahwa ada berbagai konsep tentang tentang penganugerahan ijazah.

Dalam artikel ini akan dijelaskan mulai dari konsep ijazah dari Sistem Pendidikan Islam (SPI) beserta persyaratan untuk mendapatkan, bentuk ujian, usia saat mendapatkan, peran ijazah, jenis-jenis dan penggolongan ijazah, hingga poin-poin yang tertuang dalam ijazah. Sebagai pembanding, akan disajikan pula dalam artikel ini ijazah dalam Sistem Pendidikan Barat (SPB). Dengan demikian, akan tampaklah perbedaan di antara keduanya.

Oleh karena itu, artikel ini bertujuan untuk menyajikan selayang pandang pengijazahan dalam SPI, agar dapat diketahui secara umum, terutama di negara-negara di luar Uni Emirat Arab.

\section{METODE}

Artikel ini merupakan studi pustaka berupa rangkuman materi dari berbagai sumber yang relevan untuk pembahasan pengijazahan SPI.

Studi pustaka diawali dengan pembahasan kata ijazah secara etimologi dan istilah untuk mengetahui beberapa konsep tentang ijazah. Dari makna-makna tersebut, maka dapat diterapkan makna apa saja yang releven dengan pokok bahasan dalam makalah ini.

Langkah selanjutnya adalah menampilkan deskripsi pengijazahan dalam SPI mulai dari persyaratan untuk mendapatkan, bentuk ujian, usia saat mendapatkan, peran ijazah, jenis-jenis dan penggolongan ijazah, hingga poin-poin yang tertuang dalam ijazah. Dilanjutkan dengan deskripsi ijazah dalam SPB sebagai pembanding. Artikel disimpulkan untuk mencari perbedaan signifikan antara pengijazahan pada SPI dan SPB.

\section{PEMBAHASAN}

\section{A. Ijazah dalam Sistem Pendidikan Islam}

Secara etimologi, Ibn Manzur, menyebutkan dalam kitabnya Lisan al-Arab bahwa kata Ijazah bersumber dari bahasa Arab yakni dari kata dasar ajaza yang bermakna 'duduk di kursi'(Ibn Manzur, 1990). Sementara, Imam an-Nawawi di dalam kitabnya at-Taqrib wa at-Taysir li Ma'rifati Sunan al-Bashir al-Nazir menyatakan bahwa kata dasar Ajaza bermakna 'air'; yang digunakan untuk 
mengairi sawah atau untuk menghilangkan dahaga (bin Said \& bin Adam, n.d.). Sementara itu, al-Fayruzabadi di dalam al-Qamus al-Muhit menyatakan bahwa arti kata dasar ajaza tersebut adalah mengesahkan atau memberikan hak pada seseorang (Ābādī, 2007).

Sedangkan secara istilah, ijazah, menurut Ibn Manzur adalah hak yang diberikan untuk meligitimasi ilmu yang telah dipelajarinya (Ahmad, Kadir, \& Hussin, 2016). Imam an-Nawawi menyatakan bahwa pada dasarnya seorang mahasiswa meminta ijazah dari profesornya untuk menghilangkan dahaganya akan ilmu pengetahuan. Sedangkan al-Fayruzabadi menambahkan tentang hak yang diberikan tersebut adalah hak untuk mengajar (Safran, 2018).

Dari ketiga pendapat tersebut diatas, penulis lebih cenderung kepada alFayruzabadi karena lebih relevan dengan tema sentral dalam makalah ini yaitu bahwa ijazah adalah hak untuk mengajar.

Ijazah sebagai nomina adalah selembar kertas yang berisi informasi tentang: (1) institusi pengijazah, (2) data pribadi penerima ijazah, dan (3) daftar mata kuliah yang menunjukan expertise tertentu; sebagaimana yang terjadi di dunia pendidikan secara umum. Mahasiswa sebuah Perguruan Tinggi pada fakultas dan program studi tertentu, saat lulus akan memperoleh selembar ijazah. Ijazah biasanya diberikan bersamaan dengan selembar transkrip yang berisi informasi tentang daftar mata kuliah dan nilainya (Sarwanto, 2015).

Namun, pengijazahan dalam konsep SPI adalah pemberian hak untuk mengajar kepada seseorang yang telah menempuh studi dan dinyatakan lulus dalam ujian lisan oleh Pengijazah (al-Mujiz), professor, pensyarah, syeikh, guru, dsb (Makdisi, 1970). Wujudnyapun berbeda dengan yang ada di SPB; yakni berupa buku yang memuat daftar kitab yang telah dipelajari berikut silsilah perawinya.

\section{B. Pengijazahan dalam SPI}

Sesuai ajaran yang dianut oleh kaum muslimin, seseorang yang paling berwenang untuk menyampaikan ilmu adalah Rasulullah $S A W$, insan pilihan Allah yang menerima wahyu melalui malaikat jibril. Ilmu tersebut bersifat pengajaran untuk mencapai kebahagian hidup baik di dunia maupun di akhirat. Ilmu ini diajarkan secara lisan oleh Rasulullah SAW kepada para Sahabatnya: Abu Bakar, Umar, Ustman, dan Ali. Para sahabat kemudian meneruskan ajarannya kepada at- 
Taabi'in, lalu at-Taabi'in menyampaikan kepada Tabi' at-Taabi'in. Demikian seterusnya hingga sampai kepada para ulama (mufrad) (Syobromalisi, 2011).

Proses ini seperti pada periwayatan sebuah hadist (Nazlianto \& Lc, 2018). Hadist yang berisi Sabda, perbuatan, taqrir dan sifat Rasulullah SAW, atau asSunnah, diperdengarkan, dibaca, dihafal dan dilafalkan dengan keras dan jelas; sebagaimana yang dilakukan Rasulullah SAW di hadapan Jibril a.s ketika menerima wahyu pertama dari Allah di Gua Hira saat beliau sedang berkhalwat.

Pengijazahan sendiri dapat dilakukan dengan dua cara, yakni secara lisan dan tulisan. Namun, berdasarkan sejarah pengijazahan secara lisan lebih banyak dilakukan dibandingkan secara tulisan (Cochran, 2011).

Sebelum konsepnya berkembang luas, pengijazahan sebenarnya adalah salah satu metode untuk menentukan kesahihan periwayatan sebuah hadist untuk dapat diklasifikasikan berdasarkan darajat kepercayaan (thiqah) seseorang perawi melalui ucapan lisannya (Mohamed \& Othman, 2017). Para periwayat hadist (muhadistin) adalah golongan pertama yang menggunakan istilah ini demi pemeliharaan ilmu. Mereka jugalah Muslim pertama yang menyadari pentingnya penulisan ilmu agar dapat digunakan secara luas dalam bidang lain.

Ijazah yang berisi nama-nama lalu dikompilasikan dalam buku atau bentuk tulisan lain yang mengesahkan pemiliknya dan orang lain setelahnya untuk kemudian disyahkan oleh al-Mujiz; yang maknanya pemegang ijazah memiliki hak untuk mengajarkannya kepada orang lain. Ijazah berasosiasi dengan kata sami'ah dari kata dasar sama' yang artinya mendengar. Oleh karenanya dalam kurun waktu selanjutnya dikenal istilah ijazah pendengaran (Ijazat as-Sama'); yaitu ditransfer dengan metode lisan (Ramli, Ahmad, \& Zin, 2017).

Prosedur pengijazahan lisan dilakukan dengan membaca teks secara hafalan. Proses pembacaan ini sesuai dengan ajaran al - Quran dan al-Hadist. Mendengar dan membaca saling terkait satu sama lain dan kadang-kadang menjadi berasosiasi antara qara'ah dan sami'ah.

Informasi dalam ijazat as-Sama' meliputi: 1) penganugerah atau disebut Musmi',2) pembaca ijazah disebut Qaari'; yakni orang yang menerima ijazah, dan 3) penulis ijazah atau disebut sebagai kaatib as-sama', kaatib at - Tabaqah ataupun mustbit as-Sama'. Pada awal mulanya, ijazah ditulis pada lembar kosong yang terdapat di dalam kitab yang dipelajari. 
Ijazah dalam meriwayatkan al-Hadist berarti memberikan hak kepada seseorang untuk meriwayatkannya kepada orang lain (Mas'ud, 1998). Selain dimaknai sebagai hak untuk meriwayatkan hadist, ijazah juga bisa digunakan untuk disiplin ilmu lain, seperti: hak untuk mengajar hukum (al-Ijazah li at-Tadris) (Smith II, 2015) dan fiqih. Demikian juga ilmu-ilmu lain (Makdisi, 1970). Oleh sebab itu S1 Kependidikan di beberapa negara Uni Emirat Arab memberikan gelar akademik (Lc.) yang berarti licenced (berhak) untuk mengajar. Ijazah untuk mengajar ini pertama kali dikeluarkan di Baghdad pada awal tahun ke-3 Hijriah. Kemudian, pada tahun ke-4 menyebar ke seluruh negara Islam.

\section{Tahap Ujian Akhir}

Ijazah akan dikeluarkan setelah dewan penguji merasa puas dengan performa mahasiswa melalui ujian lisan (Bahjat \& Albidewi, n.d.). Dalam Ujian ini, mahasiswa diminta memberikan argumentasi untuk mempertahankan sekumpulan tesis hasil karyanya; apabila terbukti cukup kompeten, ijazah akan dianugerahkan. Ujian ini meliputi uji penguasaan kitab-kitab yang telah selesai dipelajari oleh mahasiswa (Bahjat \& Albidewi, n.d.). Sebagai contoh, Ibrahim bin Makram al-Shirazi telah dianugerahi ijazah setelah diuji oleh dua orang professor yang sekaligus pemberi fatwa dikeluarkannya lisensi untuk mengajar hukum-hakam. Pada waktu yang sama, yang bersangkutan juga telah diuji penguasaannya oleh beberapa professor lain yang kitab-kitabnya telah dipelajari oleh calon penerima ijazah. Perkembangan pengijazahan dalam bidang fiqh ini sepesat bidang hadist.

\section{Usia Penerima Ijazah}

Berdasarkan ketentuan, sebuah ijazah hanya diberikan kepada mahasiswa pada usia matang, yakni sekitar usia 30 atau 40 tahun ke atas. Sebagian ulama tidak memperkenankan untuk menganugerahkan ijazah kepada mahasiswa dalam usia muda (Laffan, 2004).

Namum demikian Allah terkadang memberikan keistimewaan kepada hamba-hambaNya yang terpilih. Ulama besar fiqh dari Syria, al-Awza'i, misalnya telah dapat mengeluarkan fatwanya dalam usia tiga belas tahun. Muslim bin Khalid, salah seorang ulama besar mazhab as-Syafi'e telah dianugerahi ijazah pada usia lima belas tahun. Tajud Din as-Subki juga mendapat ijazah untuk mengajar fiqh dan hak mengeluarkan fatwa pada usia delapan belas tahun, dll. Kemahiran berhujah 
dan berargumentasi mereka didukung oleh daya ingat luar biasa. Semua atas kehendak Allah.

Pada dasarnya wewenang untuk memberikan ijazah dimiliki oleh seseorang secara pribadi, maknanya seorang profesor atau ulama boleh mengeluarkannya (Böttcher, 2002). Namun sebagian ulama sangatlah teliti dan tidak mudah dalam memberikan ijazah. Misalnya seorang ulama fiqh, Abu Ishaq Ibrahim bin Yahya alDimashqi terkenal; sebagai ulama beliau sangat berhati-hati (tegas) sehingga banyak mahasiswanya mengalami kesulitan dalam mendapatkan ijazah beliau. Tidak jarang, beliau tega 'menggagalkan' mahasiswanya karena dianggap belum layak. Begitu juga dengan 'Ustman bin Sa'id Ustman Abu Umar.

Demikian juga sebaliknya, ada juga mahasiswa yang dengan rendah hati menyatakan bahwa mereka belum mahir dan layak untuk menerima ijazah. Mereka menyadari betapa berat tanggung jawabnya yang diembannya setelah diberi ijazah. Seperti pada kasus Ibnu Hubaysh, beliau berkata: "Wahai Tuan, saya tidak layak menerima ijazah." Hal itu tak lain hanyalah suatu sikap kehati-hatian atau kerendahhatian.

\section{E. Pengijazahan Sebagai Hak Pribadi}

Wewenang untuk memberikan ijazah hanya melekat pada ulama, yaitu seseorang yang menguasai ilmu agama, terutama kepakaran dalam bidang hukumhakam Islam atau seorang faqih (jama'-fuqaha'). Seorang faqih yang menganugerahkan ijazah kepada mahasiswanya, maka pada hakekatnya ulama tersebut sedang menggunakan hak pribadi yang melekat pada dirinya sebagai seorang individu; dan tidak sedang mewakili organisasi di bawah fakultas tertentu sebagaimana yang terjadi di SPB.

Pemerintah dalam hal ini tidak boleh melakukan intervensi. Tiada seorangpun boleh mendikte mereka dalam urusan pengijazahan. Dengan cara inilah, nilai-nilai agama dapat ditegakkan. Ilmu berasosiasi dengan kebijaksanaan ulama bukan pemerintah. Pun bukan oleh universitas atau asosiasinya. Islam tidak seperti gereja yang tidak memiliki kekuatan bagaikan paderi.

Meski institusi milik para ulama bebas dari campur tangan pemerintah dan tidak memerlukan izin pemerintah untuk mendirikannya, pemerintah mengatur agar sebagian saham institusi tersebut dimiliki oleh pemerintah. Sebagai dampak 
positifnya jajaran pemerintahan juga berisikan ulama. SPI ini termasuk salah satu undang-undang yang bersifat individu.

\section{F. Jenis Jenis Ijazah}

Ada enam jenis ijazah yang masing-masing akan diuraikan sebagai berikut:

1. Ijazah Istimewa; Ijazah ini dianugrahkan oleh seseorang kepada orang lain. Ada empat hal yang tercantum pada ijazah yang paling bergensi ini; 1) nama pensyarah, 2) nama mahasiswa, 3) nama mata kuliah, dan 4) pengakuan dari profesor dengan predikat 'ajaztu' (Falahi, n.d.)

2. Ijazah Biasa; Ijazah ini juga menyebutkan nama professor, tetapi nama mata kuliah tidak dinyatakan. profesor akan menyatakan dengan lisan bahwa mahasiswanya telah mendapat hak untuk mengajar tanpa merinci mata kuliah atau kitab-kitab yang telah dipelajari.

3. Ijazah Kelompok; nama profesor tercantum, akan tetapi penerimanya merupakan satu kelompok dan nama mereka tidak dicantumkan. Sebuah hak diberikan untuk menyampaikan ilmu dalam sesuatu mata kuliah tertentu,

4. Ijazah atas Kitab; Ijazah jenis ini sangat detail. Seorang profesor membuat pernyataan bahwa mahasiswanya telah selesai mempelajari kitab tertentu dan telah hafal. Ijazah ini hanya diberikan setelah pelajar tersebut membuktikan kecakapannya.

5. Ijazah berdasarkan Surat Keputusan; ijazah ini hanya untuk mata kuliah hadist, diberikan setelah seorang alim menulis hadist tertentu dan mempresentasikannya dihadapan kelompok anak didiknya, disertai dengan 'surat keputusan' yang menyatakan bahwa yang bersangkutan telah diberi hak untuk meriwayatkannya kepada orang lain tentang apa yang telah ditulis oleh profesornya.

6. Ijazah Kehormatan; hanya diberikan kepada dan oleh antar ulama. Diantara mereka terjadi saling tukar menukar ijazah ini sebagai tanda hormat dan menghargai jasa mereka; seperti yang terjadi pada professor exchanges.

Benang merah yang dapat ditarik dari masing-masing jenis ijazah di atas adalah bahwa ijazah bersifat peribadi bukan institusi. Dan inilah keistimewaan dari pengijazahan dalam SPI (Schmidtke, 2006). 


\section{G. Peran Ijazah}

Peran ijazah bagi kemajuan mahasiswa masa kini di era kemajuan peradaban Islam sangatlah penting. Ijazah telah memuat informasi tentang siapa penganugrah ijazah termasuk ilmu-ilmu yang dipelajari lengkap dengan sanad-sanadnya yang sampai kepada Rasulullah SAW sehingga dianugerahi hak untuk menurunkan ilmunya.

Akan sangat sulit untuk melakukan judgement terhadap orang yang tidak memiliki ijazah. Orang tersebut tidak akan diketahui kemampuannya dan hak-hak akademik yang melekat pada pofesinya. Ijazah adalah justifikasi keilmuan, yang secara jelas memberi gambaran tentang apa yang dapat secara akademis dan profesional dilakukan oleh pemegang ijazah.

\section{H. Penggolongan Ijazah}

Sebagaimana telah disebutkan bahwa ada Ijazah Istimewa. Ijazah jenis ini awalnya hanya diaplikasikan pada ilmu hadist, kemudian disusul oleh bidangbidang lain seperti kaligrafi, tariqah (religious order), sufisme, puisi/sajak, kesusasteraan, dan sains.

Ijazah dalam bidang kaligrafi yang jenisnya bermacam-macam, diberikan kepada mahasiswa oleh seseorang profesor yang menyatakan mereka layak untuk bekerja sebagai penulis khat, penyalin atau pencetak dan kerani, sebagai pejabat kerajaan (Parvez, n.d.). Beberapa contoh ijazah jenis ini dapat dijumpai Muradi's Silk al-Durar fi A'yan al-Thani 'Ashar dan dalam Ugur Derman's Hattat Icazetnameleri.

Dahulu, peminat ijazah ini sangat berlimpah karena bisa menjadi pintu untuk tergabung sebagai pejabat kerajaan; yang saat itu sedang giat-giatnya menyalin kitab-kitab karena mensin pencetak belum tersedia.

Sementara itu, ijazah dalam bidang tariqah kesufian memiliki cakupan yang luas; baik dari sudut fisikal maupun spiritual. Ijazah tariqah kesufian secara spiritual bermakna penunjukkan pengganti sang profesor sebagai syeikh untuk mengajar kitab-kitab kesufian. Hal ini pernah dilakukan oleh Syeikh 'Abbas Afandi kepada Hafiz 'Umar Afandi dalam tariqah Ummu Sinan, salah satu cabang Naqshibandiyyah, pada 1321 A.H., di Skopje. Hal ini juga yang terjadi pada Syeikh Nizamuddin Awliya dari gurunya Syeikh Faridud-Din Gani-Shakar untuk mengajar kitab Tamhidi karangan Abu Shakur Salimi tentang asas-asas Keimanan. 
Pengijazahan di dalam bidang puisi dan sajak juga pernah dilakukan, misalnya ijazah yang dianugerahkan oleh 'Ali bin Muhammad bin Mahfuz al-'Alawi kepada anaknya Siddiq bin 'Ali pada 691 A.H berupa lisensi untuk mengajar puisi 'Umar bin al-Farid. Isi dari ijazah tersebut adalah sebagai berikut:

"Wahai anakku, Siddiq ibn 'Ali, pelajar yang berilmu, 'adil dan bersemangat tinggi, Semoga Allah mengilhamkannya lisensi dan jalan yang lurus untuk diikuti, dan melindunginya dari kejahatan orang-orang terkutuk dan dari azab siksaan, telah mempelajari puisi 'Umar bin al - Farid dari saya kecuali satu puisi yang diawali dengan : Sa'iq al-Az'an Tatwy al-Bid Tay, maka, dengan ini saya memberi hak kepadanya untuk membacanya setelah saya sebagaimana saya membacanya setelah Syeikh Fakhrud-Din al-Iraqi."

Pada bidang medis, yang mulai diminati pada abad ke-10 M., mewajibkan seseorang konsultan medis/bakal doktor untuk lulus ujian dan mendapat ijazah berupa hak praktek. Sebagai contoh ijazah medis ada di dalam kitab Ibn Abi 'Usaybi'ah's Tabaqat al - Atibba.

\section{Struktur dalam Ijazah}

Berikut ini adalah bentuk ijazah yang dikeluarkan oleh sebagian besar SPI. Ijazah biasanya dimulai dengan: 1) Basmalah, diikuti 2) Hamdalah, dan 3) sholawat atas Nabi Muhammad SAW. Selanjutnya adalah 4) Predikat atas keilmuan dan manfaatnya, diikuti dengan 5) potongan ayat-ayat al-Quran dan Al-Hadist yang berkaitan dengan manfaat ilmu keilmuan; misalnya "Katakanlah : Adakah sama orang-orang yang mengetahui dan orang-orang yang tidak mengetahui?" disambung dengan hadist "Bila seseorang berjalan untuk mencari ilmu, Allah akan membuka untuknya salah satu jalan menuju surga".

Yang ke 6) sanad yang merupakan hal yang sangat diutamakan oleh ulama Salaf dalam mengkaji ilmu hadist, apakah hadist tersebut benar-benar datang dari Nabi SAW atau sebaliknya (Alias, Mohamad, Nor, \& Saad, 2018). Tidak hanya hadist, sanad ini lalu diaplikasikan pada bidang-bidang lain dalam rangka menjamin keaslian, kesahihan dan kualitas ilmu yang disampaikan. Abdullah bin Mubarak menerangkan "Sanad itu sebahagian dari ad-Deen, sekiranya tidak karena sanad, tentu semuan orang bisa berbicara apapun sesuai kehendaknya".

Silsilah penyampai atau perawi suatu ilmu akan kembali kepada Allah; kecuali ijazah dalam bentuk kitab, silsilah akan berakhir pada penulisnya. Sementara ijazah ilmu hadist akan bermuara kepada orang yang mengumpulkan 
dan menulis hadist tersebut karena hadist-hadist di dalam suatu kitab mempunyai sebilangan para perawi yang berbeda dan ia akhirnya akan kembali kepada Rasulullah SAW.

Namun, menuliskan nama semua perawi yang hidup sejak zaman Rasulullah SAW hingga ke zaman ulama pengumpul hadist itu sulit, sanadnya akan sangat panjang dan memakan tempat yang banyak jika harus dituliskan dalam ijazah. Oleh karenanya, terkadang yang tertulis dalam ijazah hanyalah sebagian perawi tanpa menurunkan kekuatan dari suatu hadist.

Terdapat juga 7) nama pensyarah dan 8) nama pelajar. Dalam hal ini pensyarah menyebutkan nama pelajar yang diijazahi. 9) Perkembangan akademik pelajar juga dilampirkan untuk menunjukkan kualitas ilmu seseorang pelajar. Selain itu, 10) para pensyarah berkesempatan memberikan penghargaan kepada guru mereka sendiri dengan menyebutkan nasab ilmunya. 11) Nama kitab - kitab dan subjek yang dipelajari juga dinyatakan dalam ijazah.

Seorang pensyarah akan memberikan 12) wejangan kepada penerima tentang bagaimana menggunakan ilmu sebaik-baiknya, mengajar muridnya kelak, berperan sebagai ulama masyarakat, tidak melupakan gurunya dan senantiasa memohon kepada Allah SWT agar senantiasa diberi kekuatan. Sebagai penutup, ijazah lazimnya akan diakhiri dengan 13) doa, 14) tanggal dikeluarkannya ijazah dan 15) pengesahan dari pensyarah disertai tanda tangan atau stempel resmi atau kedua - duanya.

Untuk (16) nama institusi jarang dituliskan. Kecuali jika diadakan forum resmi, maka tempat diadakan forum tersebut (universitas) akan dituliskan. Begitu pula bila nama pensyarah disebut, maka nama universitasnya otomatis tersebut dalam ijazah.

Hanya dengan cara tersebut, peta geografis Ilmu-ilmu Islam dapat terlihat; yakni tentang: di mana, kapan, bagaimana proses pembelajaran dan mata pelajaran apa saja yang dipelajari, serta bagaimana kemajuan sosial dan politiknya sehingga perkembangan ilmu pengetahuannya tercatat dalam sejarah.

\section{J. Perbedaan Pokok antara Ijazah pada SPI dan SPB}

Seperti telah disebutkan dimuka bahwa pengijazahan sudah berkembang di dunia Pendidikan Islam sejak abad ke-4 A.H (abad ke-10 M). Baru dua abad 
kemudian yakni pada abad ke-12, tradisi ini muncul di Latin Barat. Sebagaimana pengijazahan di dunia SPI, pengijazahan di Latin barat juga bermakna lisensi untuk mengajar atau licentia docendi. Walaupun menurut George Makdisi, tiadak ada bukti sejarah yang membuktikan adanya ijazah ini di Greece maupun di Roma. Tidak ada juga ijazah yang dikeluarkan oleh Kristiani Timur Byzantine yang terkait langsung dengan pendidikan klasik dari Greece.

Pernyataan mereka tentang telah dikenalnya system ijazah pada abad ke-12 tidak didukung oleh bukti sejarah. Namun hal yang menarik adalah pernyataan dari Daniel Haneberg, yang telah melakukan kajian terhadap system Pendidikan Islam; dia menyampaikan" Saya rasa pemberian lisensi yang kita (Barat) miliki itu pada mulanya bersumber dari sistem Pendidikan Islam".

George Maksidi menambahkan bahwa tahapan perolehan ijazah dan licentia docendi menurut tidak jauh berbeda:

From initial training in the literacy arts, to embarking on the long course of study leading to the mastership, passing through the ranks of scholar (mutafaqqih) and fellow (faqih), representing the undergraduate and graduate level, assisting the master as ordinary repetitor (mu'id) or extraordinary docent (mufid), including the work of building up repertories of disputed questions (masa'il khilafiyah, quaestiones disputatae), the student practice of quizzing one another (mudhakarah,collatio), disputing for practice with fellow students, or with masters in class (munazarah, disputatio), disputation based on the confrontation of conflicting opinions (khilaf, sic et non), and the mastery of dialectic (jadal, dialectica), and finally, obtaining the licence to teach (ijazah li at-Tadris, licentia docendi), and incepting by giving the inaugural lesson or lecture (dars iftitahi, inceptio).

Satu hal yang perlu dicatat bahwa ijazah telah berkembang lebih dari satu abad sebelum munculnya licentia docendi. Pada perkembangannya licentia docendi telah diubah menjadi selembar ijazah. Seperti yang terjadi di Perancis, semula hak mengajar melekat pada ijazah yang diberikan kepada seseorang setelah menempuh studi pada sebuah Perguruan Tinggi. Namun kemudian terjadi reformasi pendidikan pada 1973 dan mencapai puncaknya pada 1976 yang berdampak pada perubahan licentia docendi tersebut. Hal tersebut tidak pernah terjadi pada ijazah dalam SPI, kecuali pada tempat-tempat khusus.

Pada dasarnya perbedaan antara ijazah pada SPI dan SPB terletak pada tiga hal:

1. Ijazah SPI bukan wewenang institusi untuk menerbitkannya, melainkan oleh professor. Tidak ada stempel resmi atau pengesahan dari universitas. Seorang profesor bertanggung jawab penuh untuk menguji dan mengijazah 
mahasiswanya. Dengan cara ini kualitas ilmu tetap terjaga. Sebaliknya pada SPB, tidak ada ikatan langsung antara professor dan penerima ijazah. Hal ini bisa menimbulkan masalah bila mahasiswa Perguruan Tinggi membludak yang berdampak tidak terkontrolnya penguasaan ilmu mahasiswa. Kedekatan antara profesor dan mahasiswa pada SPB baru terjadi pada level pasca sarjana karena jumlahnya cenderung lebih sedikit.

2. Ijazah SPI menyebutkan nama mata kuliah (madah), berikut kitab yang telah dipelajari dan dikuasai beserta keterangan silsilah penyampai yang bermuara pada penulis kitab. Sementara dalam ijazah SPB, hanya berupa daftar mata kuliah dan nilai-nilainya.

3. Dari segi wujudnya, ijazah dalam SPI berbentuk buku yang terkadang terdiri dari 20 halaman atau lebih. Sementara ijazah SPB hanya berupa satu lembar sertifikat.

\section{SIMPULAN DAN SARAN}

\section{A. Simpulan}

Agama Islam adalah agama akhir jaman yang merupakan penutup dan penyempurna agama-agama samawi sebelumnya. Sistem Pendidikan Islam memiliki keunikan tersendiri, yang salah satunya adalah adanya tradisi penganugrahan ijazah (pengijazahan) dari seorang profesor kepada mahasiswanya. Dikatakan bahwa pengijazahan adalah hak prerogatif profesor yang tidak dapat diganggu gugat dan bukanlah wewenang institusi untuk menganugerahkan ijazah. Terntunya penganugrahan ijazah itu dilakukan setelah melalui ujian-ujian tertentu dan oleh guru dinyatakan lulus. Seorang mahasiswa yang telah memiliki ijazah berarti yang bersangkutan telah diberi mandat (hak) untuk menyampaikan apa yang telah dipelajari dari Perguruan Tinggi tertentu.

Telah banyak dijelaskan jenis-jenis dan ragam ijazah termasuk perbedaanperbedaan satu sama lain. Yang perlu dicatat tentang pengijazahan ini adalah bahwa SPI memiliki tradisi unik, dan sangat berbeda dengan SPB. Semua itu dilakukan demi menjaga kualitas, kesahihan, ilmu yang dipelajari. 


\section{B. Saran}

Saran untuk para peneliti dan pemerhati Peradaban Islam adalah bahwa peneliti di masa mendatang supaya melakukan penelitian menyangkut tradisitradisi lain dalam Islam, misalnya dengan metode etnografi. Hanya setelah mengetahui akar sebuah tradisi, seseorang bisa berfikir dan bertindak bijak dalam menyikapi segala hal.

\section{DAFTAR PUSTAKA}

Ābādī, A.-F. (2007). al-Qāmūs al-Muhịṭ. Dār al-Ma'rifah.

Ahmad, M. N., Kadir, M. N. A., \& Hussin, H. (2016). Pengaplikasian Kaedah Tafsir alQur'an dengan Qira'at oleh Muhammad Said bin Umar di dalam Tafsir Nurul Ihsan. AL-TURATH JOURNAL OF AL-QURAN AND AL-SUNNAH, 1(1), 65-73.

Alias, N., Mohamad, K. A., Nor, Z. M., \& Saad, N. H. M. (2018). Sanad Qiraat dan Hadis: Analisa Terhadap Proses Pengijazahan. Ma'ālim Al-Qur’ān Wa Al-Sunnah, 14(15).

Bahjat, Y., \& Albidewi, I. (n.d.). Redesigning Educational Systems Using IJAZA Structure. bin Said, K., \& bin Adam, J. (n.d.). Corak Tariq Sanad Pengajian Al-Quran di Negeri Pahang. QURANICA-International Journal of Quranic Research (, 1(1).

Böttcher, A. (2002). Sunni and Shi 'i Networking in the Middle East. Mediterranean Politics, 7(3), 42-63.

Cochran, J. A. (2011). Disillusionment with Higher Education in the Middle East and the United States. In Forum on Public Policy Online (Vol. 2011). ERIC.

Falahi, G. N. (n.d.). Development of Hadith.

Ibn Manzur, M. (1990). Lisan al-'arab. Beirut: Dar Al-Sadir.

Laffan, M. (2004). An Indonesian community in Cairo: Continuity and change in a cosmopolitan Islamic milieu. Indonesia, (77), 1-26.

Makdisi, G. (1970). Madrasa and university in the middle ages. Studia Islamica, (32), $255-264$.

Mas'ud, A. (1998). Mahfūz al-Tirmisī (d. 1338/1919): An Intellectual Biography. Studia Islamika, 5(2).

Mohamed, A., \& Othman, F. M. (2017). Penyelesaian Perbezaan Penilaian Pengkritik Hadith Ke Atas Kredibiliti Perawi: Kajian Ke Atas Perawi Bagi Hadith-Hadith Di Dalam Kitab Mastika Hadith Jilid 3. AL-TURATH JOURNAL OF AL-QURAN AND ALSUNNAH, 2(1), 65-73. 
Nazlianto, R., \& Lc, M. A. (2018). HADĪTS ZAMAN RASULULAH SAW DAN TATACARA PERIWAYATANNYA OLEH SAHABAT. Al-Mursalah, 2(2).

Parvez, A. (n.d.). Origination, Development and the Types of Islamic Calligraphy (Khatt Writing).

Ramli, F. Z. M., Ahmad, M. H. A.-S., \& Zin, S. M. M. (2017). Salasilah Sanad Kitab Turath Hadis Tokoh Ulama Kelantan Tuan Guru Haji Abdullah Lubok Tapah (19332008). HADIS, 1-23.

Safran, A. Bin. (2018). Metodologi A. Mukti Ali Dalam Penafsiran Alqurān: Analisis Terhadap Kitab Tafsir Alqurān di Nusantara. Jurnal Penelitian Medan Agama.

Sarwanto, S. (2015). Surat Keterangan Pendamping Ijazah Bagi Mahasiswa Lulusan Pendidikan Fisika dan Tantangan Menghadapi Masyarakat Ekonomi ASEAN. In PROSIDING: Seminar Nasional Fisika dan Pendidikan Fisika (Vol. 6).

Schmidtke, S. (2006). Forms and functions of 'licences to transmit'(Ijàzas) in 18thCentury-Iran:'Abd Allàh al-Mùsawì al-Jazà" irì al-Tustarì's (1112-73/1701-59) ijàza kabìra. SOCIAL, ECONOMIC AND POLITICAL STUDIES OF THE MIDDLE EAST AND ASIA, 95.

Smith II, M. V. (2015). Islamic Pedagogy and Critical Thinking: Does Islamic pedagogy want critical thinkers?

Syobromalisi, F. A. (2011). Membahas kitab tafsir klasik-modern. 